\title{
Extracellular Vesicles from Hyperammonemic Rats Induce Neuroinflammation and Motor Incoordination in Control Rats
}

\author{
Paula Izquierdo-Altarejos ${ }^{1,+}{ }^{,}$Andrea Cabrera-Pastor ${ }^{2,+}{ }^{+}$, Hernan Gonzalez-King ${ }^{3}$, \\ Carmina Montoliu ${ }^{2,4}$ and Vicente Felipo ${ }^{1, * \mathbb{D}}$ \\ 1 Laboratory of Neurobiology, Príncipe Felipe Research Center, 46012 Valencia, Spain; pizquierdo@cipf.es \\ 2 Health Research Institute INCLIVA, 46010 Valencia, Spain; \\ acabrera@cipf.es (A.C.-P.); cmontoliu@incliva.es (C.M.) \\ 3 Regenerative Medicine and Heart Transplantation Unit, Health Research Institute La Fe, 46026 Valencia, \\ Spain; hernangkg10@gmail.com \\ 4 Pathology Department, University of Valencia, 46010 Valencia, Spain \\ * Correspondence: vfelipo@cipf.es; Tel.: +349-63-289-680 \\ + These authors contributed equally to this work.
}

Received: 11 February 2020; Accepted: 25 February 2020; Published: 28 February 2020

\begin{abstract}
Minimal hepatic encephalopathy is associated with changes in the peripheral immune system which are transferred to the brain, leading to neuroinflammation and thus to cognitive and motor impairment. Mechanisms by which changes in the immune system induce cerebral alterations remain unclear. Extracellular vesicles (EVs) seem to play a role in this process in certain pathologies. The aim of this work was to assess whether EVs play a role in the induction of neuroinflammation in cerebellum and motor incoordination by chronic hyperammonemia. We characterized the differences in protein cargo of EVs from plasma of hyperammonemic and control rats by proteomics and Western blot. We assessed whether injection of EVs from hyperammonemic to normal rats induces changes in neuroinflammation in cerebellum and motor incoordination similar to those exhibited by hyperammonemic rats. We found that hyperammonemia increases EVs amount and alters their protein cargo. Differentially expressed proteins are mainly associated with immune system processes. Injected EVs enter Purkinje neurons and microglia. Injection of EVs from hyperammonemic, but not from control rats, induces motor incoordination, which is mediated by neuroinflammation, microglia and astrocytes activation and increased IL-1 $\beta, \mathrm{TNF} \alpha$, its receptor TNFR1, NF- $\mathrm{KB}$ in microglia, glutaminase I, and GAT3 in cerebellum. Plasma EVs from hyperammonemic rats carry molecules necessary and sufficient to trigger neuroinflammation in cerebellum and the mechanisms leading to motor incoordination.
\end{abstract}

Keywords: hepatic encephalopathy; $\mathrm{TNF} \alpha ; \mathrm{TNF} \alpha$ receptor TNFR1; glial activation

\section{Introduction}

Patients with liver cirrhosis may present minimal or clinical hepatic encephalopathy (HE), a complex neuropsychiatric syndrome leading to cognitive and motor alterations which reduces quality of life and life span of the patients. Hyperammonemia and inflammation act synergistically to induce minimal HE (MHE) [1-5].

Studies in patients and in animal models show that MHE appearance is associated with changes in the peripheral immune system that are transferred to the brain, inducing neuroinflammation, which in turn leads to cognitive and motor impairment [6-11]. 
Changes in the immune system also lead to cerebral alterations in pathologies associated to sustained peripheral inflammation such as diabetes, rheumatoid arthritis, obesity, and chronic kidney disease, as well as neurological and neurodegenerative diseases such as schizophrenia, Parkinson's and Alzheimer's disease [12-20].

The mechanisms by which changes in the immune system induce alterations in brain in response to sustained inflammation are not well understood. There is increasing evidence that extracellular vesicles (EVs) may play an important role in this process [21]. EVs are membranous vesicles released by most cells [22]. EVs play a main role in the mediation of immune and inflammatory responses, and in diseases with a significant inflammatory component $[23,24]$.

EVs may act as mediators of neuroinflammation [25] and may transmit pathological effects from the periphery to the brain. For example, EVs are increased in serum of children with autism spectrum disorder and stimulate human microglia to secrete IL-1 $\beta$, which may explain what triggers inflammation in brain of these children [26].

EVs of sporadic amyotrophic lateral sclerosis (ALS) patients transport pathological proteins which might play a role in prion-like propagation of ALS disease [27].

Han et al. [28] showed that intravenous treatment of mice with exosomes from serum of patients with Parkinson's disease evoke protein aggregation, trigger dopamine neuron degeneration, induce microglial activation, and cause movement defects.

In contrast, EVs from mesenchymal stem cells have neuroprotective effects [29-32].

EVs may therefore induce either pathological or therapeutic effects. To characterize the role of EVs in the mediation of pathological effects from the periphery to the brain in hyperammonemia would allow a better understanding of the mechanisms responsible for MHE and may allow the identification of new therapeutic procedures to prevent or reverse the associated cognitive and motor alterations.

The aim of this work was to assess whether EVs play a role in the induction of glial activation and neuroinflammation in cerebellum and motor incoordination by chronic hyperammonemia. Chronic hyperammonemia in rats induces peripheral inflammation, which mediates the induction of neuroinflammation, leading to alterations in neurotransmission and cognitive impairment. All these effects of hyperammonemia on brain are prevented by inhibiting the induction of peripheral inflammation with anti-TNF $\alpha$ [10]. This rat model is therefore useful to investigate the mechanisms by which peripheral inflammation induces changes in brain and the role of EVs in this process.

To assess if EVs play a role in the mechanisms by which hyperammonemia induces changes in the brain, we isolated EVs from plasma of hyperammonemic rats and assessed whether injection of these EVs to normal rats induces similar changes in neuroinflammation in cerebellum and motor incoordination to those exhibited by hyperammonemic rats.

We have shown that induction of motor incoordination by hyperammonemia is mainly mediated by induction of microglia and astrocytes activation in cerebellum, which is associated to increased $\mathrm{TNF} \alpha$, which activates its receptor TNFR1, leading to increased NF- $\mathrm{KB}$ in microglia and expression of glutaminase, which increases glutamate, leading to reversal of the GABA transporter GAT3 function in activated astrocytes and increased GABAergic neurotransmission, finally inducing motor incoordination [9-11]. We have therefore analyzed the effects of injecting EVs from hyperammonemic rats to control rats on these mechanisms in cerebellum.

We isolated EVs from plasma of hyperammonemic rats, injected them to control rats and assessed if they transmit the deleterious effects shown in hyperammonemia to the brain. We analyzed the effects on glial activation, neuroinflammation, the changes in TNF $\alpha$, TNFR1, NF- $\mathrm{KB}$ in microglia, glutaminase, GAT3 in cerebellum, and evaluated motor incoordination.

\section{Materials and Methods}

Model of chronic hyperammonemia. Male Wistar rats (6-7 weeks -old) were made hyperammonemic by feeding an ammonium containing diet as described by Felipo et al. [33] during 5 weeks. Rats were sacrificed and plasma was obtained and stored at $-80^{\circ} \mathrm{C}$. 
Extracellular vesicles isolation. Extracellular vesicles were isolated by ultracentrifugation. Plasma ( $3 \mathrm{~mL}$ ) was thawed on ice, diluted to $20 \mathrm{~mL}$ with sterile PBS and centrifuged at $2000 \mathrm{~g}$ for $20 \mathrm{~min}$ at $4{ }^{\circ} \mathrm{C}$. Supernatants were collected, filtered through 0.22 um sterile filters and centrifuged at $150,000 \times g$ for 16 $\mathrm{h}$ at $4{ }^{\circ} \mathrm{C}$. Supernatants were removed and pellets were washed by ultracentrifugation at $150,000 \times g$ for $2 \mathrm{~h}$ and $110,000 \times g$ for $70 \mathrm{~min}$ at $4{ }^{\circ} \mathrm{C}$. Pellets were resuspended in $100 \mu \mathrm{L}$ of PBS and stored at $-80^{\circ} \mathrm{C}$. Six microliters were used for protein quantification by the bicinchoninic acid method.

Nanoparticle Tracking Analysis. Distribution profile, size and quantity of vesicles were assessed by Nanoparticle Tracking Analysis with a NanoSight NS300 system (Malvern Panalytical, Malvern, UK) using a 1:100 dilution of exosome samples. Transmission Electron Microscopy. Electron microscopy was performed as described by Thery et al. [34]. Briefly, isolated vesicles were loaded onto carbon-coated copper grids and contrasted with $1 \%$ uranyl acetate. Samples were examined with a transmission electron microscope and images were acquired using a digital camera.

Analysis of protein cargo of EVs by immunoblotting. Samples were subjected to electrophoresis and immunoblotting as described by Felipo et al. [33]. Primary antibodies used were against Alix (1:1000, Abcam), Flotillin-2 (1:500, Fisher), Hsp70 (1:1000, Proteintech), CD9 (1:1000, Abcam), Glutamine Synthetase (1:5000, BD Biosciences), TIMP-3 (1:1000, Abcam), TNF $\alpha$ (1:500, RD systems), TNFR1 (1:500, Abcam), Galectin-3 (1:1000, Abcam). Anti-actin (1:5000, Abcam) was used as protein loading control. Secondary antibodies were anti-rabbit, anti-rat, or anti-goat IgG conjugated with alkaline phosphatase (1:4000, Sigma). Membranes were scanned and band intensities were quantified using Alpha Imager 2200 version 3.1.3.

Proteomic analysis. Differential expression of proteins was analyzed in the SCSIE University of Valencia using EVs isolated from plasma of 8 control and 8 hyperammonemic rats. An equivalent amount of all the samples were pooled to build the spectral library from a 1D SDS-PAGE gel. The run corresponding to the library was cut and digested with sequencing grade trypsin as described by Shevchenko et al. [35]. Five microliters of each digested pool were loaded onto a trap column (NanoLC Column, $3 \mu \mathrm{m} \mathrm{C18-CL,} 75 \mu \mathrm{m} \times 15 \mathrm{~cm}$; Eksigent) and desalted with $0.1 \%$ trifluoroacetic acid at $3 \mu \mathrm{L} / \mathrm{min}, 5 \mathrm{~min}$. Peptides were loaded onto an analytical column (LC Column, $3 \mu \mathrm{m} \mathrm{C18-CL,} 75 \mu \mathrm{m}$ $\times 12 \mathrm{~cm}$, Nikkyo) equilibrated in 5\% acetonitrile, $0.1 \%$ formic acid. Peptide elution was carried out with a linear gradient of 5\% to $40 \%$ B in $60 \mathrm{~min}$ (A: $0.1 \%$ formic acid; B: acetonitrile, $0.1 \%$ formic acid) for at a flow rate of $300 \mathrm{~nL} / \mathrm{min}$. Peptides were analyzed in a mass spectrometer nanoESI qQTOF (5600 TripleTOF, ABSCIEX) and in ProteinPilot search engine (Sciex) to generate peak list. For individual SWATH analysis $20 \mu \mathrm{g}$ of protein was loaded in a 1D SDS-PAGE gel. Sample was digested with trypsin as above. Peptides were analyzed in the mass spectrometer and the tripleTOF was operated in swath mode, in which a $0.050 \mathrm{~s}$ TOF MS scan from $350-1250 \mathrm{~m} / \mathrm{z}$ was performed, followed by $0.080 \mathrm{~s}$ product ion scans from $350-1250 \mathrm{~m} / \mathrm{z}$ on the 32 defined windows ( $3.05 \mathrm{sec} /$ cycle). The Swath windows used were: 15 Da window widths from 450 to $1000 \mathrm{Da}, 37$ windows. Individual SWATH injections were randomized and analyzed by Peak View 2.1.

Injection of isolated vesicles to rats. Male Wistar rats ( 2 months-old, $n=22$ rats per group) were intravenously injected twice in the tail vein with $50 \mu \mathrm{g}$ of protein of isolated vesicles from either control or hyperammonemic rats, in $300 \mu \mathrm{L}$ of sterile PBS. A third group receiving only PBS injection was included as control. The second injection was performed one week later. The experiments were approved by the Comite de Experimentación y Bienestar Animal (CEBA) of our Center and by Conselleria de Agricultura of Generalitat Valenciana and were performed in accordance with guidelines of the Directive of the European Commission (2010/63/EU) for care and management of experimental animals. The experimental design is summarized in Figure 1.

Fluorescent labeling of extracellular vesicles. To check whether injected EVs reach the brain, we performed a parallel experiment in different rats $(n=4)$. Vesicles were labeled with the dye Dil (Sigma) as described by Jiang et al. [36]. Rats were intravenously injected with $100 \mu \mathrm{g}$ of fluorescently labeled vesicles and sacrificed by perfusion with paraformaldehyde at $72 \mathrm{~h}$. Fixed brains were collected and immediately frozen in OCT. Ten micrometer sections were cut on a cryostat and counterstained with 
Calbindin (1:500, Abcam), Iba1 (1:300, WAKO), NeuN (1:200, Millipore), GFAP (1:400, Sigma) and Alix (1:200, Abcam), followed by goat anti-rabbit or goat anti-mouse Alexa 488 secondary antibody (1:400, Invitrogen), and DAPI staining. Images were acquired with a Leica TCS SP8 inverted laser scanning confocal microscope using oil objectives: 63X Plan-Apochromat-Lambda Blue 1.4 N.A.

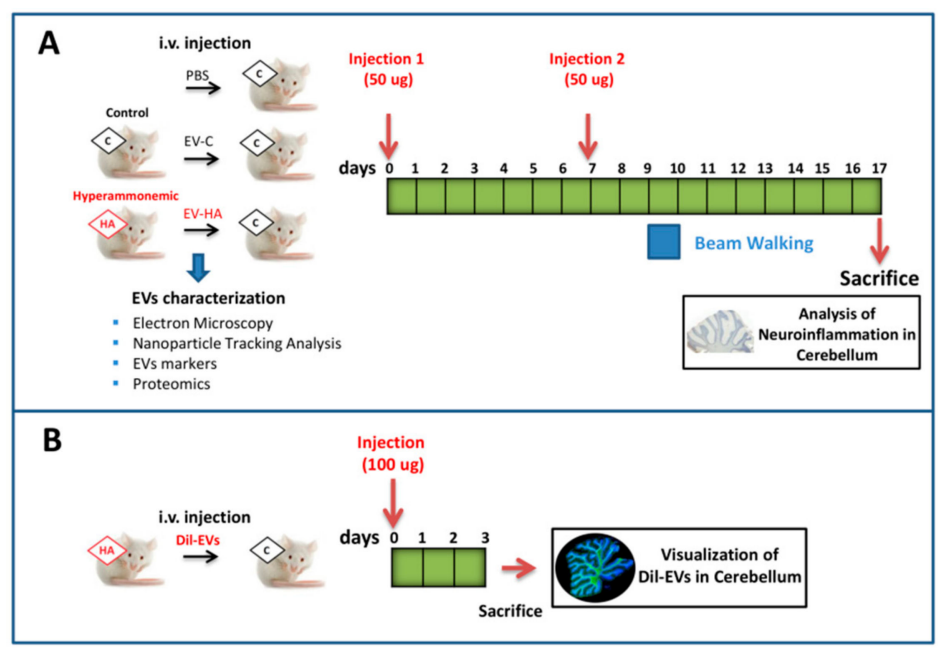

Figure 1. Experimental design. (A) Extracellular vesicles from plasma of control and hyperammonemic rats were isolated and characterized by electron microscopy, nanoparticle tracking analysis, extracellular vesicles (EVs) markers, and proteomics. Then, we intravenously injected EVs either from control or hyperammonemic rats (HA) rats into control rats. A third group received only PBS injection. Two injections of $50 \mu \mathrm{g}$ each were performed on day 0 and day 7 . Beam Walking test was performed at day 9 to study motor incoordination. Rats were sacrificed at day 17 and cerebellum was collected for neuroinflammation analysis. (B) In a parallel experiment, we injected fluorescently labeled EVs from HA rats into control rats. Rats were sacrificed after 3 days and cerebellum was collected to assess if fluorescent EVs reach this area.

Analysis of protein content in cerebellum. Rats were sacrificed by decapitation and cerebelli of 18 rats per group were dissected and homogenized. Samples were subjected to electrophoresis and immunoblotting as above. Primary antibodies used were against CD68 (1:1000, Abcam), IL-1 $\beta$ (1:500, RD Systems), TNF $\alpha$ (1:500, RD systems), TNFR1 (1:250, Abcam), Glutaminase 1 (1:1000, Novus Biologicals), and GAT-3 (1:1000, Synaptic Systems). Anti-actin (1:5000, Abcam) was used as protein loading control. Secondary antibodies were anti-rabbit, anti-goat or anti-mouse IgG conjugated with alkaline phosphatase (1:4000, Sigma).

Analysis of microglial and astrocytic activation by immunohistochemistry and immunofluorescence. Cerebelli of 4 rats per group were fixed in $4 \%$ paraformaldehyde in $0.1 \mathrm{M}$ phosphate buffer for $24 \mathrm{~h}$ and embedded in paraffin. Five micrometer sections were cut and mounted on coated slide glass. For immunohistochemistry, sections were sequentially incubated with $3 \% \mathrm{H}_{2} \mathrm{O}_{2}$ for $15 \mathrm{~min}$ to quench endogenous peroxidase activity, blocking serum (normal goat serum) and primary antibodies $\left(4^{\circ} \mathrm{C}\right.$, overnight): Iba1 (1:300, Wako) of GFAP (1:400, Sigma). Then, slides were incubated with ready-to-use Goat anti-rabbit (HRP polymer) or Goat anti-mouse (HRP polymer) secondary antibodies (Abcam) for $1 \mathrm{~h}$ and diaminobenzidine for $10 \mathrm{~min}$. Sections were counterstained with Mayer's hematoxylin (DAKO) for 5 min. For each rat, 10-12 fields at 56x magnification (Iba1 stained sections) or 40 $\times$ (GFAP stained sections) were quantified. Images were acquired with Pannoramic Viewer (3DHISTECH). Microglial activation was analyzed by measuring the area of Iba1 stained cells with IpWin 32 software program and astrocytic activation was analyzed by measuring the GFAP stained area with ImageJ software.

For immunofluorescence, sections were incubated with primary antibody against CD68 (1:100, Abcam), rabbit anti-mouse Alexa 488 secondary antibody (1:400, Invitrogen) and DAPI to visualize 
cell nuclei. For double immunofluorescence, primary antibodies were NF-kB p50 (1:200, Abcam) and Iba1 (1:300, Abcam), followed by donkey anti-mouse Alexa 488 and donkey anti-rabbit Alexa 647 secondary antibodies (1:400, Invitrogen) and DAPI. Eight images per rat were acquired with a confocal microscope using oil objectives: 63X Plan-Apochromat-Lambda Blue 1.4 N.A and the number of CD68 positive cells or number of microglial cells expressing NF- $\mathrm{kB}$ was manually counted.

Motor coordination. Beam Walking Test was performed 9 days after the first injection of EVs as described by Gonzalez-Usano et al. [37]. The number of slips committed was recorded.

Statistical analysis. Data are expressed as mean \pm SEM. All statistical analyses were performed using GraphPad Prism software 8.1.2 version. Data were analyzed by parametric T-test when comparing two groups or by one-way analysis of variance (ANOVA) followed by Tukey post hoc test when comparing three groups. A confidence level of $95 \%$ was accepted as significant.

\section{Results}

\subsection{Chronic Hyperammonemia Alters the Amount and Protein Cargo of EVs in Plasma}

We first characterized the EVs isolated from plasma of control and hyperammonemic rats. The EVs exhibited properties compatible with exosomes regarding to morphology, size and surface markers. Electron microscopy images of the isolated EVs are shown in Figure 2A. The presence of surface markers typical of exosomes was evaluated by Western blot, revealing that the isolated EVs were positive for Hsp70, Flotillin-2, and CD9 (Figure 2B). Size distribution profile was analyzed by Nanoparticle Tracking Analysis, showing that the mean diameter of EVs was $143 \pm 4 \mathrm{~nm}$ (Figure 2C).

A
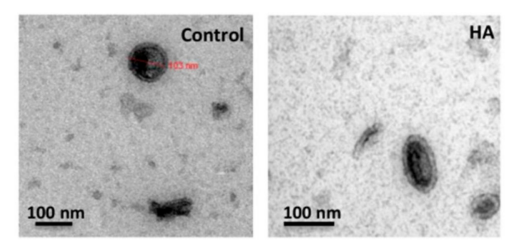

B

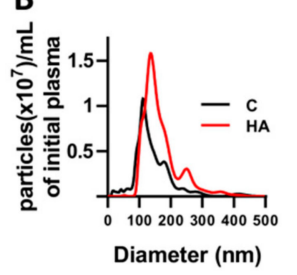

C
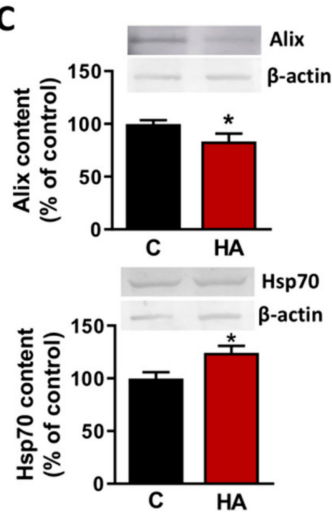
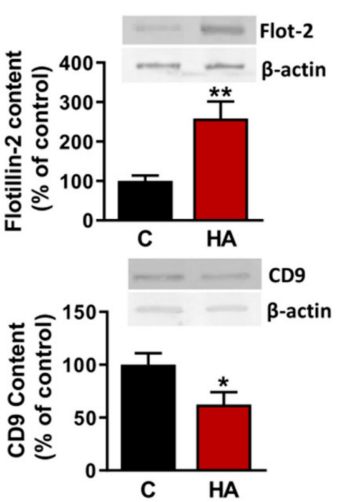

Figure 2. Characterization of extracellular vesicles isolated from plasma of control and hyperammonemic rats. (A) Representative images obtained by Transmission Electron Microscopy after negative staining. (B) Content of markers Alix $(n=16)$, Flotillin-2 $(n=7), \operatorname{Hsp} 70(n=20)$ and CD9 $(n=12)$ analyzed by Western blot. Values are expressed as percentage of protein cargo in control rats and are the mean \pm SEM. Data were analyzed by $\mathrm{t}$-test, with values significantly different from control rats indicated by asterisk $\left({ }^{*} p<0.05,{ }^{* *} p<0.01\right)$. (C) Representative size profile and number of particles obtained by Nanoparticle tracking analysis. Values of particle quantity are the mean \pm SEM of 15-18 samples per group. Data were analyzed by $\mathrm{t}$-test, with values significantly different from control indicated by asterisk $\left({ }^{*} p<0.01\right)$. We assessed if hyperammonemia alters the protein cargo of EVs by performing a proteomic analysis. After Uniprot mammalia library with False Discovery Rate (FDR) identification and analysis of individual SWATH experiments 367 proteins (FDR $<1 \%$ ) were quantified in the 16 samples. Differential expression analysis identified 124 proteins which content was different in EVs from HA or control rats. 44 proteins (12\% of total) were up-regulated, 80 proteins (22\% of total) were down-regulated, and 242 proteins ( $66 \%$ of total) remained unaltered (Figure $3 \mathrm{~A}$ ). The differentially expressed proteins identified are listed in Table 1. 
Table 1. List of up-regulated and down-regulated proteins in extracellular vesicles purified from hyperammonemic rats and obtained by SWATH analysis as indicated in methods.

\begin{tabular}{|c|c|c|c|}
\hline \multicolumn{4}{|c|}{ Down-Regulated Proteins } \\
\hline Protein Name & $P$-Value & Protein Name & $P$-Value \\
\hline $\begin{array}{l}\text { Serine (Or cysteine) peptidase inhibitor, } \\
\text { clade C (Antithrombin) }\end{array}$ & 0.011 & Pyruvate kinase PKM & 0.025 \\
\hline Apolipoprotein $\mathrm{H}$ & 0.042 & Complement component C6 & 0.005 \\
\hline Cfh protein & 0.042 & Complement C3 & 0.015 \\
\hline Carboxypeptidase B2 & 0.007 & Gelsolin & 0.008 \\
\hline Hemopexin & 0.028 & Apolipoprotein A-IV & 0.001 \\
\hline Complement component factor h-like 1 & 0.009 & Alpha-2 antiplasmin & 0.005 \\
\hline Rat apolipoprotein E protein & 0.002 & RCG33981, isoform CRA & 0.005 \\
\hline Complement $\mathrm{C} 8$ gamma chain & 0.014 & Mannan-binding lectin serine protease 1 & 0.003 \\
\hline Inter alpha-trypsin inhibitor, heavy chain 4 & 0.016 & Tetraspanin-CD9 & 0.039 \\
\hline Vitronectin & 0.019 & Proteasome subunit beta & 0.006 \\
\hline Complement factor B & 0.017 & $\mathrm{C} 9$ protein & 0.050 \\
\hline Coagulation factor XIII B chain & 0.035 & Fetub protein & 0.013 \\
\hline Complement factor $\mathrm{H}$ & 0.002 & Complement component $\mathrm{C} 8$ beta chain & 0.017 \\
\hline $\begin{array}{l}\text { Retinoic acid receptor responder } \\
\text { (Tazarotene induced) }\end{array}$ & 0.010 & $\begin{array}{l}\text { Serine (Or cysteine) proteinase inhibitor, } \\
\text { clade A (Alpha- } 1 \text { antiproteinase, } \\
\text { antitrypsin), member } 4\end{array}$ & 0.002 \\
\hline Prothrombin & 0.018 & Ig gamma-2B chain $\mathrm{C}$ region & 0.036 \\
\hline Complement factor I & 0.008 & Ig gamma- $2 \mathrm{C}$ chain $\mathrm{C}$ region & 0.039 \\
\hline Kininogen-1 & 0.021 & Kallikrein B, plasma 1 & 0.026 \\
\hline MCG1038839 & 0.002 & Complement C4B (Chido blood group) & 0.026 \\
\hline $\begin{array}{l}\text { Macrophage stimulating } 1 \text { (Hepatocyte } \\
\text { growth factor-like) }\end{array}$ & 0.005 & RCG55135, isoform CRA_b & 0.019 \\
\hline Apolipoprotein B-100 & 0.010 & Complement C7 & 0.048 \\
\hline LOC299567 protein (Fragment) & 0.019 & Apolipoprotein C-II (Predicted) & 0.007 \\
\hline Coagulation factor XII & 0.034 & $\begin{array}{l}\text { Inter-alpha-trypsin inhibitor heavy } \\
\text { chain H3 }\end{array}$ & 0.039 \\
\hline Complement $\mathrm{C} 8$ alpha chain & 0.013 & MASP-3 protein (Fragment) & 0.014 \\
\hline $\begin{array}{l}\text { Insulin-like growth factor binding protein } \\
\text { complex acid-labile subunit }\end{array}$ & 0.001 & $\begin{array}{l}\text { Inter-alpha trypsin inhibitor, heavy } \\
\text { chain } 1\end{array}$ & 0.033 \\
\hline Carboxypeptidase $\mathrm{N}$ catalytic chain & 0.013 & $\begin{array}{l}\text { Inter-alpha-trypsin inhibitor heavy } \\
\text { chain } 2\end{array}$ & 0.032 \\
\hline $\begin{array}{l}\text { Serine (Or cysteine) peptidase inhibitor, } \\
\text { clade C (Antithrombin) }\end{array}$ & 0.011 & Peroxidasin & 0.014 \\
\hline Apolipoprotein $\mathrm{H}$ & 0.042 & Reelin & 0.018 \\
\hline \multicolumn{4}{|c|}{ Up-regulated proteins } \\
\hline Protein Name & $P$-Value & Protein Name & $P$-Value \\
\hline Polymeric immunoglobulin receptor & 0.009 & Myeloperoxidase & 0.011 \\
\hline CD5 antigen-like & 0.002 & Major urinary protein & 0.002 \\
\hline Ig kappa chain V19-17-like & 0.042 & $\begin{array}{l}\text { Brain cDNA, clone MNCb-5810, tissue } \\
\text { inhibitor of metalloproteinase } 3 \text { (Timp3) }\end{array}$ & 0.010 \\
\hline RCG21066 & 0.010 & Urinary protein 1 & 0.035 \\
\hline Collectin sub-family member 11 & 0.039 & Ab2-001 & 0.030 \\
\hline Ceruloplasmin & 0.015 & Thrombospondin 1 & 0.005 \\
\hline C4b-binding protein beta chain & 0.047 & Coagulation factor XI & 0.001 \\
\hline Urinary protein 2 & 0.042 & $\begin{array}{l}\text { Ficolin (Collagen/fibrinogen domain } \\
\text { containing) } 1\end{array}$ & 0.0003 \\
\hline $\begin{array}{l}\text { Heat shock protein family A (Hsp70) } \\
\text { member } 5\end{array}$ & 0.024 & Fc fragment of IgG-binding protein & 0.001 \\
\hline Thrombospondin-4 & 0.004 & Galectin-3-binding & 0.001 \\
\hline Glutamine synthetase & 0.016 & Alpha-2-macroglobulin & 0.0003 \\
\hline HGF activator & 0.031 & Ficolin-2 & 0.002 \\
\hline
\end{tabular}


A

Proteomic in exosomes

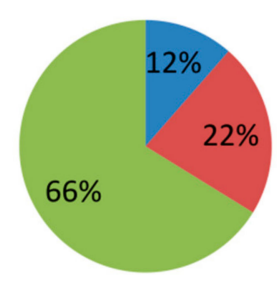

367 Total Protein

upregulated

Downregulated

Not changed
B

\section{Category Distribution}

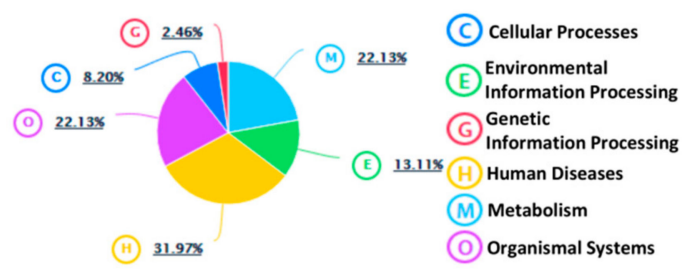

C

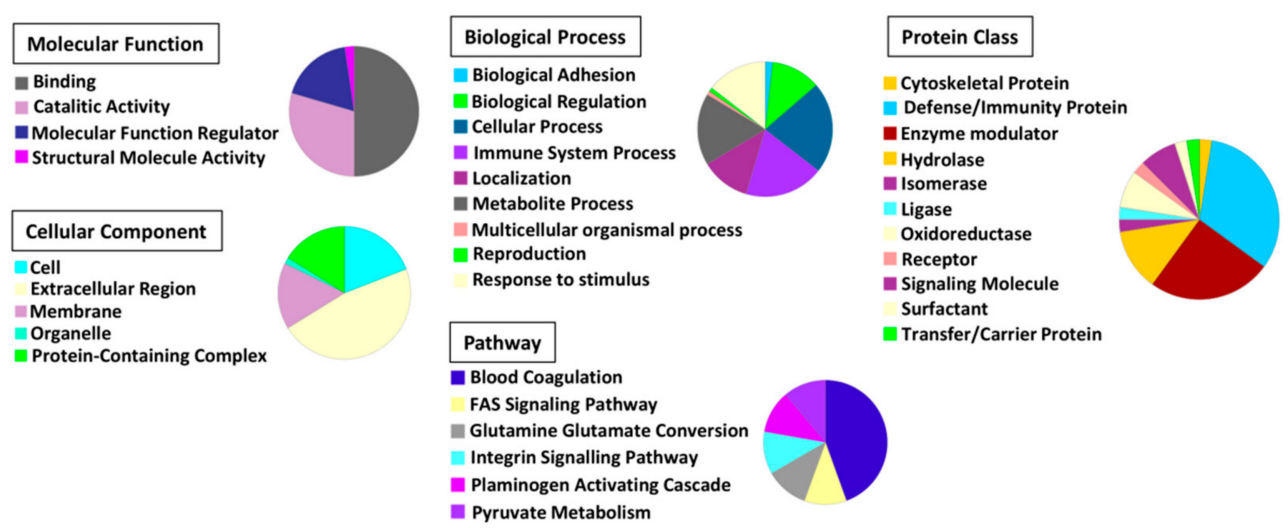

Figure 3. Proteomic profiling of extracellular vesicles purified from plasma and differently expressed in hyperammonemic rats respect to control. (A) Number of total proteins identified and percentage of up-regulated and down-regulated proteins, (B) Category distribution from Paintomics analysis and (C) Gene Ontology (GO) analysis to determine molecular function, cellular components, biological processes, pathways and protein class for the 124 proteins differently expressed in hyperammonemia, plotted with the percentage of each term.

The amount of EVs was increased $(p<0.05)$ in hyperammonemic rats to 1.77-fold of control rats (Figure 2C). Different markers of EVs are differentially altered by hyperammonemia. EVs from hyperammonemic rats show increased levels of Flotillin-2 $(259 \pm 42 \% ; p<0.01)$ and Hsp70 $(124 \pm 7 \% ; p$ $<0.05)$ while the levels of Alix $(83 \pm 7 \% ; p<0.05)$ and CD9 $(62 \pm 11 \% ; p<0.05)$ are reduced compared to control rats (Figure 2B).

Proteomic category distribution analysis using the PaintOmics 3 application showed that $32 \%$ of the proteins are related to human disease, $22 \%$ to metabolism and organismal systems, $13 \%$ to environmental information processing, $8 \%$ to cellular processes, and $2.5 \%$ to genetic information processing (Figure 3B).

To gain insight into the potential biological function of proteins differentially expressed we applied Gene Ontology (GO) analysis (Figure 3C). GO annotations are classified in five categories: Cellular component, molecular function, biological process, pathway, and protein class. Significant differences in EVs content were related with proteins activated in the extracellular region and cell surface and with binding and catalytic activity. The differences in EVs proteins are mainly associated with biological processes of immune system, response to stimulus, metabolic processes, glutamine/glutamate conversion, integrin and FAS signaling pathways. Defense/immunity proteins, enzymes modulator and receptors are some protein classes differentially expressed in EVs from hyperammonemic rats (Figure 3C).

We confirmed by Western blot the changes in some of the proteins identified as up-regulated or down-regulated (see Table 1) in hyperammonemia by the proteomic analysis (Figure 4). The contents of glutamine synthetase (Figure 4A), TIMP-3 (Figure 4B) and Hsp70 (Figure 4C) were increased to $422 \pm$ $105 \%(p<0.01) ; 131 \pm 11 \%(p<0.05) ;$ and $124 \pm 6 \%(p<0.05)$, respectively, in EVs from hyperammonemic rats compared to controls. The contents of the heavy (Figure 4D) and light (Figure 4E) chains of IgG 
and of CD9 (Figure 4F) were reduced to $70 \pm 8 \%(p<0.05) ; 89 \pm 4 \%(p<0.05)$ and $62 \pm 12 \%(p<0.05)$, respectively, in EVs from hyperammonemic rats compared to controls.
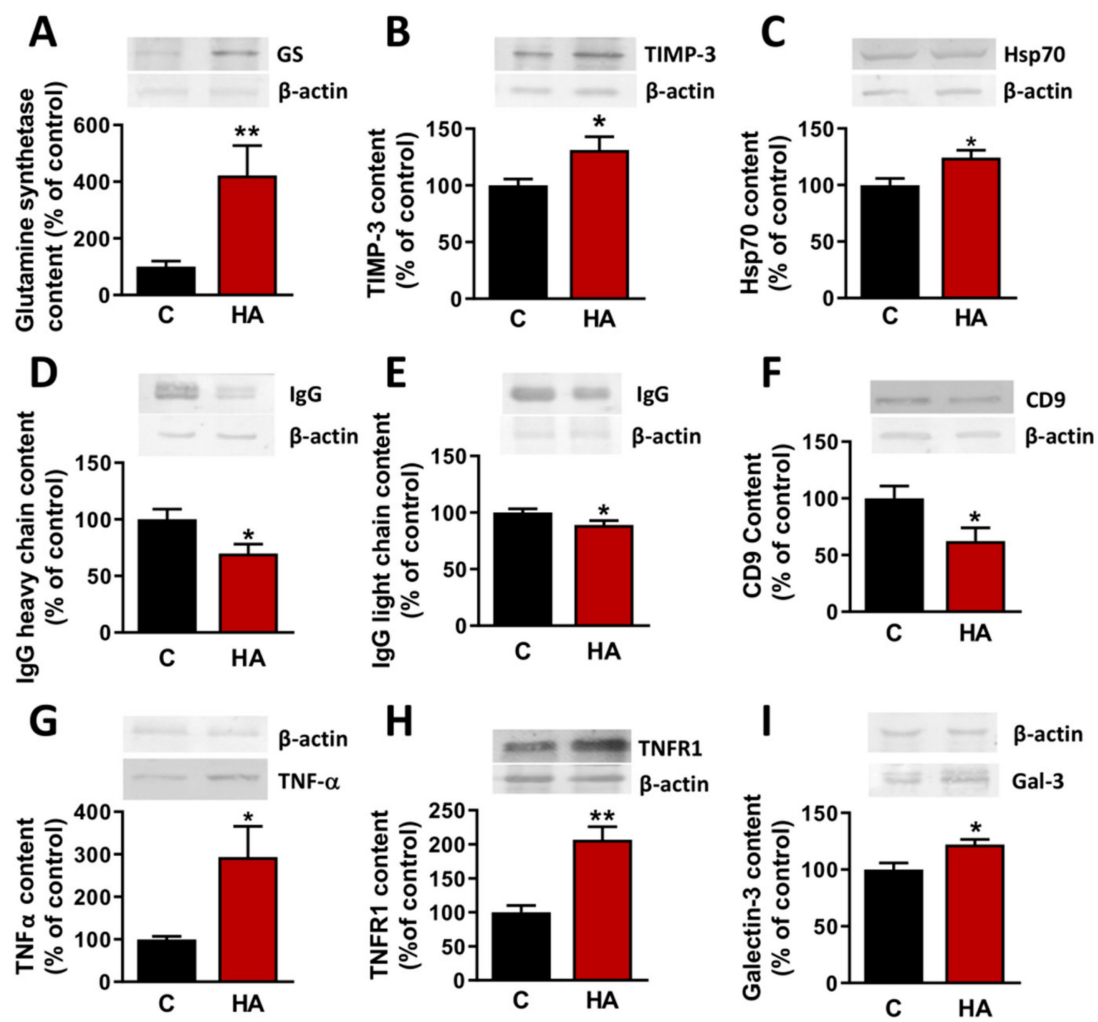

Figure 4. Extracellular vesicles protein cargo analyzed by Western blot. Content of (A) glutamine synthetase $(n=8),(\mathbf{B})$ TIMP-3 $(n=8),(\mathbf{C})$ Hsp70 $(n=20),(\mathbf{D})$ IgG heavy chain $(n=12)$, (E) IgG light chain $(n=16),(\mathbf{F})$ CD9 $(n=12),(\mathbf{G})$ TNF $\alpha(n=9),(\mathbf{H})$ TNFR1 $(n=8-10)$, (I) Galectin-3 $(n=7-13)$. Values are expressed as percentage of protein cargo in control rats and are the mean \pm SEM. Data were analyzed by t-test, with values significantly different from control rats indicated by asterisk $\left({ }^{*} p<0.05\right.$, ** $p<0.01)$.

We also analyzed the content of proteins which could mediate some of the hyperammonemia-induced alterations in cerebellum by Western blot. The content of TNF $\alpha$ (Figure 4G), of the TNF $\alpha$ receptor TNFR1 (Figure $4 \mathrm{H}$ ) and of galectin-3 (Figure $4 \mathrm{I}$ ) were increased to $213 \pm 50 \%(p<$ $0.05) ; 207 \pm 19 \%(p<0.001)$; and $122 \pm 5 \%(p<0.02)$, respectively, in EVs from hyperammonemic rats compared to controls.

\subsection{Injection of EVs from Hyperammonemic Rats Induces Neuroinflammation in Cerebellum in Control Rats}

We confirmed that injected EVs reached the cerebellum (Figure 5). DIL-labeled EVs (red signal) co-localized with Purkinje neurons (Figure 5A), neurons in white matter (Figure 5B), and microglial cells in molecular layer (Figure 5C) and in white matter (Figure 5D). No co-localization with astrocytes was observed (Figure 5E). The red fluorescence signal of Dil-labeled EVs co-localized with Alix, a marker of EVs, confirming that it corresponds to injected labeled EVs (Figure 5F).

We then assessed if injection of EVs from plasma of hyperammonemic rats may transmit deleterious effects to the brain of normal rats. EVs from hyperammonemic rats induced activation of microglia in the molecular layer of cerebellum (Figure $6 \mathrm{~A}$ ), reducing its area $(p<0.05)$ compared to rats injected with PBS (Figure 6F). This effect was specific for EVs from hyperammonemic rats and was not induced by EVs from control rats. Similar microglial activation was observed in white matter (Figure 6B,G). This was further supported by the increased labeling of CD68 (Figure 6D,I), a marker of activated microglia. 

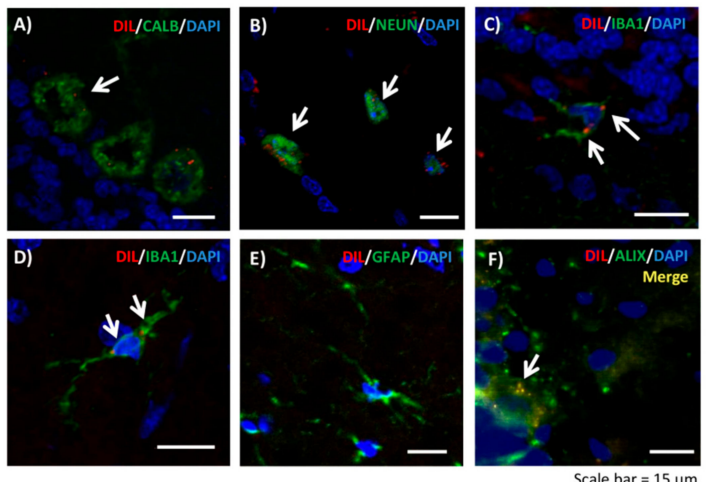

Figure 5. Intravenously injected dil-labeled extracellular vesicles (red) reach the cerebellum after 72 h. Co-localization was found with (A) Purkinje neurons, (B) neurons located in white matter, (C) microglial cells in the molecular layer, and (D) microglial cells in white matter. (E) No co-localization was observed with astrocytes in white matter. (F) We confirmed that red fluorescence signal co-localizes with Alix, a marker of extracellular vesicles. Scale bar $=15 \mu \mathrm{m}$.

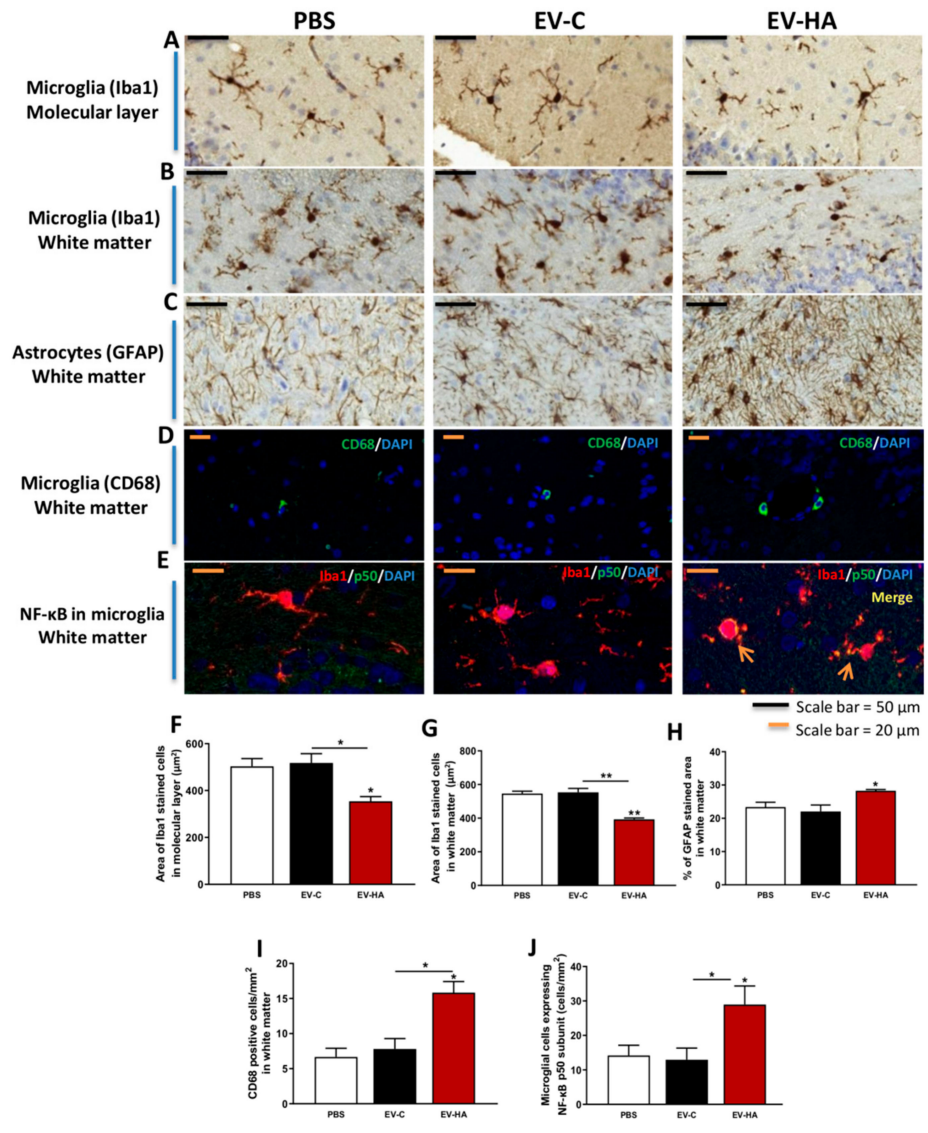

Figure 6. Effects of injected vesicles on microglial and astrocytic activation in cerebellum analyzed by immunohistochemistry/immunofluorescence. Representative images of (A) immunohistochemistry against Iba-1 in molecular layer and (B) white matter, (C) immunohistochemistry against GFAP in white matter, (D) immunofluorescence of CD68 in white matter and (E) NF-kB p50 subunit expression in microglial cells in white matter. (F) Area of microglia (Iba1 stained cells) in molecular layer and (G) white matter. (H) Percentage of GFAP stained area in white matter. (I) Number of activated microglia (CD68 positive cells) in white matter. (J) Number of microglial cells expressing NF-kB p50 subunit per $\mathrm{mm}^{2}$ in white matter. One-way ANOVA with Tukey post-hoc test was performed to compare all groups. Values are the mean \pm SEM of 3-4 rats per group. Values significantly different from PBS-injected rats are indicated by asterisk $\left({ }^{*} p<0.05,{ }^{* *} p<0.01\right)$. 
EVs from hyperammonemic rats also induced astrocytes activation in white matter (Figure 6C), increasing the GFAP stained area $(p<0.05)$ compared to rats injected with PBS or EVs from control rats (Figure 6H).

We also analyzed the content of pro-inflammatory markers in cerebellum by Western blot. The content of CD68 (Figure 7A), IL-1 $\beta$ (Figure 7B) and TNF $\alpha$ (Figure 7C) was increased to $126 \pm 7 \%(p<$ $0.05) ; 148 \pm 10 \%(p<0.01)$; and $152 \pm 17 \%(p<0.05)$, respectively, in cerebellum of rats injected with EVs from hyperammonemic rats compared to rats injected with PBS or EVs from control rats.
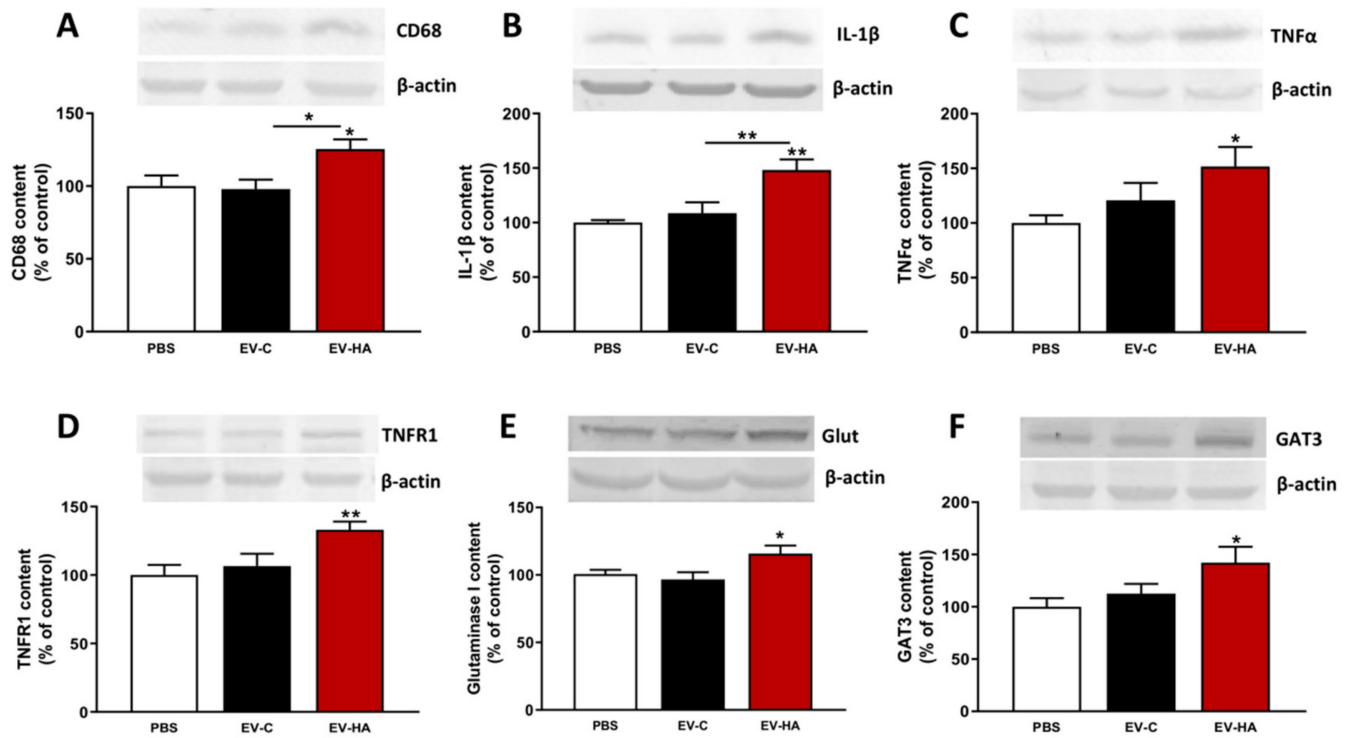

Figure 7. Total content of proteins linked with neuroinflammation in cerebellum of injected rats analyzed by Western blot. Content of (A) CD68 $(n=9-11)$, (B) IL-1 $\beta(n=5-7),(\mathbf{C})$ TNF $\alpha(n=9),(\mathbf{D})$ TNFR1 ( $n=6-11)$, (E) Glutaminase $1(n=10-13)$, and (F) GAT-3 $(n=10-12)$ in cerebellum homogenates. Representative images of the blots of each protein and the load control ( $\beta$-actin) are shown. One-way ANOVA with Tukey post-hoc test was performed to compare all groups. Values are expressed as percentage of protein content in PBS-injected rats and are the mean \pm SEM. Values significantly different from PBS or EV-C group are indicated by asterisk $\left.{ }^{*} p<0.05,{ }^{* *} p<0.01\right)$.

Injection of EVs from hyperammonemic rats induces motor incoordination and the underlying mechanisms in cerebellum in control rats.

Induction of motor incoordination in hyperammonemic rats is mediated by increased content of $\mathrm{TNF} \alpha$ in cerebellum, which activates TNFR1, leading to increased NF- $\mathrm{KB}$ in microglia and glutaminase, which increases GAT3 in activated astrocytes and GABAergic neurotransmission, leading to motor incoordination [9].

We therefore analyzed the parameters involved in this mechanism in cerebellum of rats injected with EVs from control or hyperammonemic rats. The content of TNF $\alpha$ (Figure 7C), TNFR1 (Figure 7D), glutaminase I (Figure 7E) and GAT3 (Figure 7F) were increased to $152 \pm 17 \%(p<0.05) ; 133 \pm 6 \%(p<$ $0.01) ; 116 \pm 6 \%(p<0.05)$; and $142 \pm 15 \%(p<0.05)$, respectively, in cerebellum of rats injected with EVs from hyperammonemic rats compared to rats injected with PBS or EVs from control rats.

Injection of EVs from hyperammonemic rats also increased expression of NF- $\mathrm{kB}$ in microglia while EVs from control rats did not (Figure 6E,J).

We also assessed the effects of EVs injection on motor coordination using the beam walking test. Injection of EVs from hyperammonemic rats (Figure $8 \mathrm{EV}$-hyperammonemic rats (HA)) induced motor incoordination, increasing the number of slips to $1.3 \pm 0.1(p<0.05)$ compared to $0.091 \pm 0.1$ and 0.095 \pm 0.1 in rats injected with PBS (Figure 8 PBS) or EVs from control rats (Figure 8 EV-C), respectively. As a reference, we also analyzed motor coordination in different control and hyperammonemic rats, that showed $0.8 \pm 0.1$ (Figure 8,C) and $1.2 \pm 0.1(p<0.05)$ (Figure 8, HA) slips, respectively. These data 
show that injection of EVs from hyperammonemic rats induces a lack of motor coordination similar to that induced by hyperammonemia per se.

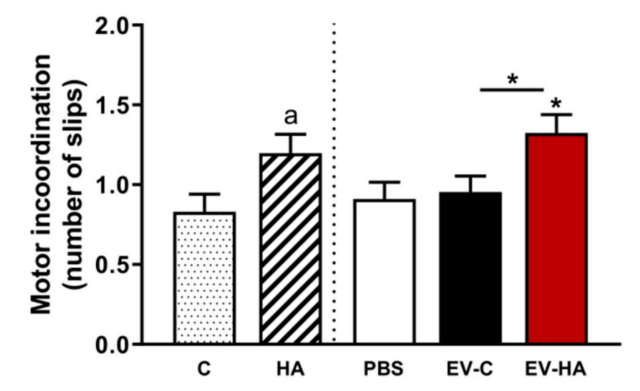

Figure 8. Vesicles isolated from plasma of hyperammonemic rats produce motor incoordination in control rats. Number of slips measured in Beam Walking test. One-way ANOVA with Tukey post-hoc test was performed to compare PBS, EV-C, and EV-HA groups. Values are the mean $\pm \mathrm{SEM}$ of 19-22 rats per group. Values significantly different from PBS or EV-C group are indicated by asterisk ${ }^{*} p<$ 0.05). Number of slips from control (C) and hyperammonemic rats (HA) without injection are included as reference $(n=32-35)$ and were analyzed by t-test. Values significantly different from control group are indicated by a $(p<0.05)$.

\section{Discussion}

This study provides relevant new insights on the mechanisms by which peripheral changes are transmitted to brain to induce MHE. Understanding these mechanisms in detail may allow designing new, more effective, therapeutic approaches.

This report shows that EVs from plasma of hyperammonemic rats injected to normal rats reach the cerebellum and are enough to trigger the mechanisms that lead to neuroinflammation and motor incoordination in chronic hyperammonemia. This supports the idea that plasma EVs would play a main role in the process by which changes in peripheral inflammation are transmitted to brain to induce neuroinflammation and cognitive and motor impairment in chronic hyperammonemia and MHE.

In contrast, injecting EVs from control rats did not induce any effect on brain. This indicates that differences in the cargo of EVs would be responsible for transmission to brain of the deleterious effects of hyperammonemia.

The analysis of differentially expressed proteins shows that the differences in EVs proteins are mainly associated with biological processes of the immune system, response to stimulus and metabolic processes and that defense/immunity proteins, enzymes modulators and receptors are differentially expressed in EVs from hyperammonemic rats. This suggests that hyperammonemia-induced inflammation play a main role in the changes in the EVs cargo. It is noteworthy that the contents of the pro-inflammatory TNF $\alpha$ and of its receptor TNFR1 are increased 2-fold in EVs in hyperammonemia. As discussed below, these proteins play a main role in the mechanism by which hyperammonemia and MHE induce motor incoordination.

The results reported also show that chronic hyperammonemia increases the number of EVs in plasma. Similar increases have been reported in other pathological situations, mostly associated to inflammation. The amount of EVs is increased in serum of patients with alcoholic hepatitis [38], $\beta$-thalassemia [39], endometrial [40] or lung cancer, correlating with tumor stage [41], obesity and diabetes mellitus [42], and chronic obstructive pulmonary disease, associated with systemic inflammation [43] and in serum of children with autism spectrum disorder [26]. Inflammation seems to trigger the increased amount of EVs in most of these situations. The results reported show that hyperammonemia increases the amount and alters the content of plasma EVs. We believe that the effects induced by injection of EVs from hyperammonemic rats to control rats are mediated by the changes in the cargo. 
Once injected, EVs reach the cerebellum, in agreement with previous studies showing that EVs can cross the blood-brain barrier $[21,25,44]$. Into the cerebellum, EVs enter Purkinje neurons, other types of neurons and microglia. The cargo of EVs from hyperammonemic rats would alter the function of these cell types. This results in induction of neuroinflammation, with microglia and astrocytes activation and increased levels of IL-1 $\beta$ and TNF $\alpha$ in cerebellum.

Injection of EVs from hyperammonemic rats also induces motor incoordination, pointing that EVs are enough to induce the neurological alterations associated to hyperammonemia. As we have recently identified the mechanism by which chronic hyperammonemia induces motor incoordination in rats [9], we analyzed whether this mechanism is induced by injection of EVs from hyperammonemic rats and we found that this is the case.

Induction of motor incoordination by chronic hyperammonemia is due to increased TNF $\alpha$ in cerebellum, which activates its receptor TNFR1, leading to increased NF-KB in microglia and glutaminase, which increases GAT3 in activated astrocytes and GABAergic neurotransmission, leading to motor incoordination [9].

We show here that injection of EVs from hyperammonemic rats also induces this mechanism in cerebellum of normal rats, with similar increases in TNF $\alpha$, TNFR1, and NF- $\mathrm{KB}$ in microglia, glutaminase and GAT3. This shows that these plasma EVs carry the molecules necessary to induce this mechanism and motor incoordination in hyperammonemia and MHE. It is noteworthy that EVs from hyperammonemic rats show increased amounts of TNF $\alpha$ and TNFR1, which trigger the mechanism leading to motor incoordination. The specific mechanism by which these proteins transported into the EVs induce the described mechanism leading to motor incoordination cannot be established with the present data and further experiments would be needed to clarify it.

Other proteins enriched in EVs in hyperammonemia may also contribute to this process. For example, galectin-3 is an inflammatory mediator [45] which may be secreted in EVs [46] and is enriched in EVs from hyperammonemic rats. Galectin-3 acts as an endogenous ligand for TLR-4 and induces TLR-4-dependent inflammatory response; its expression is increased in microglial cells activated through various neuroinflammatory stimuli [47]. Galectin-3-dependent TLR4 activation contributes to sustained microglia activation, prolonging the inflammatory response in brain [48]. A role for the galectin-3 transferred into cerebellum by EVs from hyperammonemic rats in the induction of glial activation and neuroinflammation is also possible.

A role for EVs in the transmission of deleterious effects from peripheral blood to brain has been proposed recently in a few studies in other pathological situations and models, mostly associated to sustained inflammation. Ridder et al. [21] purified EVs from blood cells of transgenic mice expressing Cre recombinase specifically in the hematopoietic lineage and injected it into brain of normal mice. These EVs transfer functional RNA to different neuronal types in brain, including Purkinje neurons. This EVs transfer is strongly promoted by peripheral inflammation and induces physiologically relevant changes as indicated by the fact that Purkinje neurons that receive EVs RNA display a different miRNA profile compared to their nonrecombined counterparts. These observations reveal the existence of a mechanism by which EVs communicate signals between the hematopoietic system and brain in response to inflammation.

Peripheral EVs may also trigger neuroinflammation. Li et al. [49] purified serum EVs from a mice model of endotoxemia with LPS and injected them to normal mice. They found that this induced microglial activation, astrogliosis, and increased expression of pro-inflammatory IL- 6 and TNF $\alpha$ in hippocampus and cerebral cortex in recipient mice. This supports that during systemic inflammation, circulating EVs may transmit to the brain signals that trigger neuroinflammation.

Intravenous injection to mice of exosomes from serum of patients with Parkinson's disease evoke symptoms similar to those suffered by the patients, including protein aggregation, dopaminergic neurons degeneration, microglial activation, and movement defects [28].

These reports, together with the present results, suggest that EVs may play a relevant role in the transmission of deleterious effects from peripheral blood to brain in different pathological situations, 
including hyperammonemia and MHE. There is overwhelming evidence that exosomes, a subtype of EVs, contribute to tumor progression and metastasis [49,50], to the immunopathology in infectious diseases [51] and to neurodegenerative diseases [52]. We show here that EVs also contribute to the induction of neuroinflammation and motor incoordination in hyperammonemia and likely MHE, in which motor incoordination is induced by similar mechanisms.

The cargo of EVs is altered differently in different pathologies and would be responsible for the transmission of the specific pathological mechanisms. The identification of the components of the cargo of EVs responsible for triggering neuroinflammation, the TNF $\alpha$-TNFR1- NF- $k B$-glutaminase-GAT3 pathway and motor incoordination in hyperammonemia and of the underlying mechanisms will allow understanding in great detail the pathological events responsible for motor incoordination. This may permit to design more effective treatments to improve motor coordination and function in hyperammonemia and MHE.

Author Contributions: P.I.-A.: most of extracellular vesicle isolation and characterization, Western blot and immunohistochemical analysis, behavioral tests, writing of the manuscript. A.C.-P.: proteomic study, study concept, supervision, analysis and interpretation of data, writing of the manuscript. H.G.-K.: contributed to extracellular vesicle isolation and characterization. C.M.: obtained funding, supervision. V.F.: obtained funding, study concept, design and supervision, analysis and interpretation of data, writing of the manuscript. All authors read and approved the final manuscript.

Funding: This work was supported in part by the Ministerio de Ciencia e Innovación Spain (SAF2014-51851-R and SAF2017-82917-R to VF; FIS PI18/00150 to CM), Consellería Educación Generalitat Valenciana (PROMETEOII/2014/033 and PROMETEOII/2018/051), and co-funded with European Regional Development Funds (ERDF). PIA has a contract from Ministerio de Ciencia, Innovación y Universidades (FPU17/01698) and ACP from Instituto de Salud Carlos III (Postdoctoral Sara Borrell, CD17/00031).

Acknowledgments: Not applicable.

Conflicts of Interest: The authors declare that they have no competing interests.

\section{References}

1. Shawcross, D.L.; Davies, N.A.; Williams, R.; Jalan, R. Systemic inflammatory response exacerbates the neuropsychological effects of induced hyperammonemia in cirrhosis. J. Hepatol. 2004, 40, 247-254. [CrossRef] [PubMed]

2. Shawcross, D.L.; Wright, G.; Olde Damink, S.W.; Jalan, R. Role of ammonia and inflammation in minimal hepatic encephalopathy. Metab. Brain Dis. 2007, 22, 125-138. [CrossRef] [PubMed]

3. Montoliu, C.; Piedrafita, B.; Serra, M.A.; Del Olmo, J.A.; Urios, A.; Rodrigo, J.M.; Felipo, V. IL-6 and IL-18 in blood may discriminate cirrhotic patients with and without minimal hepatic encephalopathy. J. Clin. Gastroenterol. 2009, 43, 272-279. [CrossRef] [PubMed]

4. Felipo, V.; Urios, A.; Montesinos, E.; Molina, I.; Garcia-Torres, M.L.; Civera, M.; Del Olmo, J.A.; Ortega, J.; Martinez-Valls, J.; Serrano, J.O; i et al. Contribution of hyperammonemia and inflammatory factors to cognitive impairment in minimal hepatic encephalopathy. Metab. Brain Dis. 2012, 27, 51-58. [CrossRef]

5. Felipo, V. Hepatic encephalopathy: Effects of liver failure on brain function. Nat. Rev. Neurosci. 2013, 14, 851-858. [CrossRef]

6. Dadsetan, S.; Balzano, T.; Forteza-Vila, J.; Agusti, A.; Cabrera-Pastor, A.; Taoro-Gonzalez, L.; Hernandez-Rabaza, V.; Gomez-Gimenez, B.; ElMlili, N.; Llansola, M.; et al. Infliximab reduces peripheral inflammation, neuroinflammation, and extracellular GABA in the cerebellum and improves learning and motor coordination in rats with hepatic encephalopathy. J. Neuroinflammation 2016, 13, 245. [CrossRef]

7. Dadsetan, S.; Balzano, T.; Forteza, J.; Cabrera-Pastor, A.; Taoro-Gonzalez, L.; Hernandez-Rabaza, V.; Gil-Perotín, S.; Núñez, L.C.; García-Verdugo, J.-M.; Agusti, A.; et al. Reducing Peripheral Inflammation with Infliximab Reduces Neuroinflammation and Improves Cognition in Rats with Hepatic Encephalopathy. Front. Mol. Neurosci. 2016, 9, 106. [CrossRef]

8. Mangas-Losada, A.; García-García, R.; Urios, A.; Escudero-García, D.; Tosca, J.; Giner-Durán, R.; Serra, M.A.; Montoliu, C.; Felipo, V. Minimal hepatic encephalopathy is associated with expansion and activation of $\mathrm{CD}^{4+} \mathrm{CD} 28^{-}, \mathrm{Th} 22$ and Tfh and B lymphocytes. Sci. Rep. 2017, 7, 6683. [CrossRef] 
9. Cabrera-Pastor, A.; Balzano, T.; Hernández-Rabaza, V.; Malaguarnera, M.; Llansola, M.; Felipo, V. Increasing extracellular cGMP in cerebellum in vivo reduces neuroinflammation, GABAergic tone and motor incoordination in hyperammonemic rats. Brain Behav. Immun. 2018, 69, 386-398. [CrossRef]

10. Balzano, T.; Dadsetan, S.; Forteza, J.; Cabrera-Pastor, A.; Taoro-Gonzalez, L.; Malaguarnera, M.; Gil-Perotin, S.; Núñez, L.C.; Casanova, B.; Castro-Quintas, A.; et al. Chronic hyperammonemia induces peripheral inflammation that leads to cognitive impairment in rats: Reversal by anti-tnfa treatment. J. Hepatol. 2019. [CrossRef]

11. Cabrera-Pastor, A.; Llansola, M.; Montoliu, C.; Malaguarnera, M.; Balzano, T.; Taoro-Gonzalez, L.; García-García, R.; Mangas-Losada, A.; Izquierdo-Altarejos, P.; Arenas, Y.M.; et al. Peripheral inflammation induces neuroinflammation that alters neurotransmission and cognitive and motor function in hepatic encephalopathy: Underlying mechanisms and therapeutic implications. Acta Physiol. 2019, 226, e13270. [CrossRef] [PubMed]

12. Díaz-Gerevini, G.T.; Repossi, G.; Dain, A.; Tarres, M.C.; Das, U.N.; Eynard, A. Cognitive and motor perturbations in elderly with longstanding diabetes mellitus. Nutrition 2014, 30, 628-635. [CrossRef] [PubMed]

13. Hamed, S.A.; Selim, Z.I.; Elattar, A.M.; Elserogy, Y.M.; Ahmed, E.A.; Mohamed, H.O. Assessment of biocorrelates for brain involvement in female patients with rheumatoid arthritis. Clin. Rheumatol. 2012, 31, 123-132. [CrossRef] [PubMed]

14. Nguyen, J.C.; Killcross, A.S.; Jenkins, T.A. Obesity and cognitive decline: Role of inflammation and vascular changes. Front. Neurosci. 2014, 8, 375. [CrossRef] [PubMed]

15. Spyridaki, E.C.; Simos, P.G.; Avgoustinaki, P.D.; Dermitzaki, E.; Venihaki, M.; Bardos, A.N.; Margioris, A.N. The association between obesity and fluid intelligence impairment is mediated by chronic low-grade inflammation. Br. J. Nutr. 2014, 112, 1724-1734. [CrossRef]

16. Miller, A.A.; Spencer, S.J. Obesity and neuroinflammation: A pathway to cognitive impairment. Brain Behav. Immun. 2014, 42, 10-21. [CrossRef]

17. Da Matta, S.M.; Janaina Matos, M.; Kummer, A.M.; Barbosa, I.G.; Teixeira, A.L.; Silva, A.C. Cognitive alterations in chronic kidney disease: An update. Braz. J. Nephrol. 2014, 36, 241-245. [CrossRef]

18. Boyer, L.; Richieri, R.; Dassa, D.; Boucekine, M.; Fernandez, J.; Vaillant, F.; Padovani, R.; Auquier, P.; Lançon, C. Association of metabolic syndrome and inflammation with neurocognition in patients with schizophrenia. Psychiatry Res. 2013, 210, 381-386. [CrossRef]

19. Garretti, F.; Agalliu, D.; Lindestam Arlehamn, C.S.; Sette, A.; Sulzer, D. Autoimmunity in Parkinson's Disease: The Role of $\alpha$-Synuclein-Specific T Cells. Front. Immunol. 2019, 10, 303. [CrossRef]

20. Takeda, S.; Sato, N.; Morishita, R. Systemic inflammation, blood-brain barrier vulnerability and cognitive/non-cognitive symptoms in Alzheimer disease: Relevance to pathogenesis and therapy. Front. Aging Neurosci. 2014, 6, 171. [CrossRef]

21. Ridder, K.; Keller, S.; Dams, M.; Rupp, A.K.; Schlaudraff, J.; Del Turco, D.; Starmann, J.; Macas, J.; Karpova, D.; Devraj, K.; et al. Extracellular vesicle-mediated transfer of genetic information between the hematopoietic system and the brain in response to inflammation. PLoS Biol. 2014, 12, e1001874. [CrossRef] [PubMed]

22. Kalra, H.; Drummen, G.P.; Mathivanan, S. Focus on Extracellular Vesicles: Introducing the Next Small Big Thing. Int. J. Mol. Sci. 2016, 17, 170. [CrossRef] [PubMed]

23. Hosseinkhani, B.; Kuypers, S.; Van den Akker, N.M.S.; Molin, D.G.M.; Michiels, L. Extracellular Vesicles Work as a Functional Inflammatory Mediator Between Vascular Endothelial Cells and Immune Cells. Front. Immunol. 2018, 9, 1789. [CrossRef] [PubMed]

24. Chan, B.; Wong, W.-Y.; Lee, M.L.; Cho, W.C.-S.; Yee, B.K.; Kwan, Y.W.; Tai, W.C.-S. Exosomes in Inflammation and Inflammatory Disease. Proteomics 2019, 19, e1800149. [CrossRef]

25. Gupta, A.; Pulliam, L. Exosomes as mediators of neuroinflammation. J. Neuroinflammation 2014, 11, 68. [CrossRef]

26. Tsilioni, I.; Theoharides, T.C. Extracellular vesicles are increased in the serum of children with autism spectrum disorder, contain mitochondrial DNA, and stimulate human microglia to secrete IL-1 $\beta$. J. Neuroinflammation 2018, 15, 239. [CrossRef]

27. Sproviero, D.; La Salvia, S.; Giannini, M.; Crippa, V.; Gagliardi, S.; Bernuzzi, S.; Diamanti, L.; Ceroni, M.; Pansarasa, O.; Poletti, A.; et al. Pathological Proteins Are Transported by Extracellular Vesicles of Sporadic Amyotrophic Lateral Sclerosis Patients. Front. Neurosci. 2018, 12, 487. [CrossRef] 
28. Han, C.; Xiong, N.; Guo, X.; Huang, J.; Ma, K.; Liu, L.; Xia, Y.; Shen, Y.; Li, J.; Jiang, H.; et al. Exosomes from patients with Parkinson's disease are pathological in mice. J. Mol. Med. 2019, 97, 1329-1344. [CrossRef]

29. Riazifar, M.; Mohammadi, M.; Pone, E.J.; Yeri, A.; Lässer, C.; Ségaliny, A.I.; McIntyre, L.L.; Shelke, G.; Hutchins, E.; Hamamoto, A.; et al. Stem Cell-Derived Exosomes as Nanotherapeutics for Autoimmune and Neurodegenerative Disorders. ACS Nano 2019, 13, 6670-6688. [CrossRef]

30. Canales-Aguirre, A.; Reza-Zaldivar, E.E.; Sapiéns, M.A.H.; Gutiérrez-Mercado, Y.K.; Sandoval-Ávila, S.; Gomez-Pinedo, U.; Márquez-Aguirre, A.L.; Vazquez-Mendez, E.; Padilla-Camberos, E. Mesenchymal stem cell-derived exosomes promote neurogenesis and cognitive function recovery in a mouse model of Alzheimer's disease. Neural Regen. Res. 2019, 14, 1626-1634. [CrossRef]

31. Vilaça-Faria, H.; Salgado, A.J.; Teixeira, F.G. Mesenchymal Stem Cells-derived Exosomes: A New Possible Therapeutic Strategy for Parkinson's Disease? Cells 2019, 8, E118. [CrossRef] [PubMed]

32. Gorabi, A.M.; Kiaie, N.; Barreto, G.E.; Read, M.I.; Tafti, H.A.; Sahebkar, A. The Therapeutic Potential of Mesenchymal Stem Cell-Derived Exosomes in Treatment of Neurodegenerative Diseases. Mol. Neurobiol. 2019, 56, 8157-8167. [CrossRef] [PubMed]

33. Felipo, V.; Miñana, M.D.; Grisolía, S. Long term ingestion of ammonium increases acetylglutamate and urea levels without affecting the amount of carbamyl phosphate synthase. Eur. J. Biochem. 1988, 176, 567-571. [CrossRef] [PubMed]

34. Théry, C.; Amigorena, S.; Raposo, G.; Clayton, A. Isolation and Characterization of Exosomes from Cell Culture Supernatants and Biological Fluids. Curr. Protoc. Cell Biol. 2006, 30. [CrossRef]

35. Shevchenko, A.; Jensen, O.N.; Podtelejnikov, A.V.; Sagliocco, F.; Wilm, M.; Vorm, O.; Mortensen, P.; Shevchenko, A.; Boucherie, H.; Mann, M. Linking genome and proteome by mass spectrometry: Large-scale identification of yeast proteins from two dimensional gels. Proc. Natl. Acad. Sci. USA 1996, 93, 14440-14445. [CrossRef] [PubMed]

36. Jiang, M.; Wang, H.; Jin, M.; Yang, X.; Ji, H.; Jiang, Y.; Zhang, H.; Wu, F.; Wu, G.; Lai, X.; et al. Exosomes from MiR-30d-5p-ADSCs Reverse Acute Ischemic Stroke-Induced, Autophagy-Mediated Brain Injury by Promoting M2 Microglial/Macrophage Polarization. Cell. Physiol. Biochem. 2018, 47, 864-878. [CrossRef] [PubMed]

37. Gonzalez-Usano, A.; Cauli, O.; Agustí, A.; Felipo, V. Pregnenolone sulfate restores the glutamate-nitric-oxide-cGMP pathway and extracellular GABA in cerebellum and learning and motor coordination in hyperammonemic rats. ACS Chem. Neurosci. 2014, 5, 100-105. [CrossRef]

38. Momen-Heravi, F.; Saha, B.; Kodys, K.; Catalano, D.; Satishchandran, A.; Szabo, G. Increased number of circulating exosomes and their microRNA cargos are potential novel biomarkers in alcoholic hepatitis. J. Transl. Med. 2015, 13, 261. [CrossRef]

39. Manakeng, K.; Prasertphol, P.; Phongpao, K.; Chuncharunee, S.; Tanyong, D.; Worawichawong, S.; Svasti, S.; Chaichompoo, P. Elevated levels of platelet- and red cell-derived extracellular vesicles in transfusion-dependent $\beta$-thalassemia/HbE patients with pulmonary arterial hypertension. Ann. Hematol. 2019, 98, 281-288. [CrossRef]

40. Dziechciowski, M.; Zapala, B.; Skotniczny, K.; Gawlik, K.; Pawlica-Gosiewska, D.; Piwowar, M.; Balajewicz-Nowak, M.; Basta, P.; Solnica, B.; Pitynski, K. Diagnostic and prognostic relevance of microparticles in peripheral and uterine blood of patients with endometrial cancer. Ginekol. Pol. 2018, 89, 682-687. [CrossRef]

41. Liu, Q.; Xiang, Y.; Yuan, S.; Xie, W.; Li, C.; Hu, Z.; Wu, N.; Wu, L.; Yu, Z.; Bai, L.; et al. Plasma exosome levels in non-small-cell lung cancer: Correlation with clinicopathological features and prognostic implications. Cancer Biomark. 2018, 22, 267-274. [CrossRef] [PubMed]

42. Pardo, F.; Villalobos-Labra, R.; Sobrevia Toledo, F.; Sobrevia, L. Extracellular vesicles in obesity and diabetes mellitus. Mol. Asp. Med. 2018, 60, 81-91. [CrossRef] [PubMed]

43. Tan, D.B.A.; Armitage, J.; Teo, T.H.; Ong, N.E.; Shin, H.; Moodley, Y.P. Elevated levels of circulating exosome in COPD patients are associated with systemic inflammation. Respir. Med. 2017, 132, 261-264. [CrossRef] [PubMed]

44. Li, J.J.; Wang, B.; Kodali, M.C.; Chen, C.; Kim, E.; Patters, B.J.; Lan, L.; Kumar, S.; Wang, X.; Yue, J.; et al. In vivo evidence for the contribution of peripheral circulating inflammatory exosomes to neuroinflammation. J. Neuroinflammation 2018, 15, 8. [CrossRef]

45. Thomas, L.; Pasquini, L.A. Galectin-3 mediated Glial Crosstalk Drives Oligodendrocyte Differentiation and (Re)myelination. Front. Cell. Neurosci. 2018, 12, 297. [CrossRef] 
46. Bänfer, S.; Schneider, M.; Dewes, J.; Strauss, M.T.; Freibert, S.A.; Heimerl, T.; Maier, U.G.; Elsasser, H.-P.; Jungmann, R.; Jacob, R. Molecular mechanism to recruit galectin-3 into multivesicular bodies for polarized exosomal secretion. Proc. Natl. Acad. Sci. USA 2018, 115, E4396-E4405. [CrossRef]

47. Wesley, U.V.; Vemuganti, R.; Ayvaci, E.R.; Dempsey, R.J. Galectin-3 enhances angiogenic and migratory potential of microglial cells via modulation of integrin linked kinase signaling. Brain Res. 2013, 1496, 1-9. [CrossRef]

48. Burguillos, M.A.; Svensson, M.; Schulte, T.; Boza-Serrano, A.; Garcia-Quintanilla, A.; Kavanagh, E. Microglia-Secreted Galectin-3 Acts as a Toll-like Receptor 4 Ligand and Contributes to Microglial Activation. Cell Rep. 2015, 10, 1626-1638. [CrossRef]

49. Li, K.; Chen, Y.; Li, A.; Tan, C.; Liu, X. Exosomes play roles in sequential processes of tumor metastasis. Int. J. Cancer 2019, 144, 1486-1495. [CrossRef]

50. Hu, J.L.; Wang, W.; Lan, X.L.; Zeng, Z.C.; Liang, Y.S.; Yan, Y.R.; Song, F.Y.; Wang, F.F.; Zhu, X.H.; Liao, W.; et al. CAFs secreted exosomes promote metastasis and chemotherapy resistance by enhancing cell stemness and epithelial-mesenchymal transition in colorectal cancer. Mol. Cancer 2019, 18, 91. [CrossRef]

51. Hosseini-Beheshti, E.; Grau, G.E.R. Extracellular vesicles as mediators of immunopathology in infectious diseases. Immunol. Cell Biol. 2018, 96, 694-703. [CrossRef] [PubMed]

52. Ciregia, F.; Urbani, A.; Palmisano, G. Extracellular Vesicles in Brain Tumors and Neurodegenerative Diseases. Front. Mol. Neurosci. 2017, 10, 276. [CrossRef] [PubMed]

(C) 2020 by the authors. Licensee MDPI, Basel, Switzerland. This article is an open access article distributed under the terms and conditions of the Creative Commons Attribution (CC BY) license (http://creativecommons.org/licenses/by/4.0/). 